\title{
Characterization of $\Delta($ G970-T1122)-CFTR, the most frequent CFTR mutant identified in Japanese cystic fibrosis patients
}

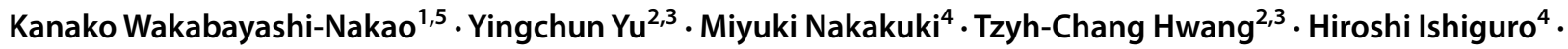 \\ Yoshiro Sohma $a^{1,2,3,5}$
}

Received: 6 April 2018 / Accepted: 19 June 2018 / Published online: 27 June 2018

๑) The Physiological Society of Japan and Springer Japan KK, part of Springer Nature 2018

\begin{abstract}
A massive deletion over three exons 16-17b in the CFTR gene was identified in Japanese CF patients with the highest frequency (about $70 \%$ of Japanese CF patients definitely diagnosed). This pathogenic mutation results in a deletion of 153 amino acids from glycine at position 970 (G970) to threonine at 1122 (T1122) in the CFTR protein without a frameshift. We name it $\Delta$ (G970-T1122)-CFTR. In the present study, we characterized the $\Delta$ (G970-T1122)-CFTR expressed in CHO cells using immunoblots and a super resolution microscopy. $\Delta$ (G970-T1122)-CFTR proteins were synthesized and core-glycosylated but not complex-glycosylated. This observation suggests that the $\Delta(\mathrm{G} 970-\mathrm{T} 1122)$ mutation can be categorized into the class II mutation like $\Delta$ F508. However, VX-809 a CFTR corrector that can help maturation of $\Delta$ F508, had no effect on $\Delta$ (G970-T1122). Interestingly C-terminal FLAG tag seems to partially rescue the trafficking defect of $\Delta$ (G970-T1122)-CFTR; however the rescued $\Delta$ (G970-T1122)-CFTR proteins do not assume channel function. Japanese, and perhaps people in other Asian nations, carry a class II mutation $\Delta$ (G970-T1122) with a higher frequency than previously appreciated. Further study of the $\Delta$ (G970-T1122)-CFTR is essential for understanding CF and CFTR-related diseases particularly in Asian countries.
\end{abstract}

Keywords Cystic fibrosis $\cdot$ CFTR $\cdot$ Mutation $\cdot$ Japanese $\cdot$ Asian

\section{Introduction}

Cystic fibrosis (CF) is one of the most common hereditary diseases in Caucasians, with an estimated incidence of 1 in 2500-3500 newborns. In Caucasians, a deletion of phenylalanine at position $508(\Delta \mathrm{F} 508)$ is the most common CFassociated mutation present in nearly $90 \%$ of CF patients [1,

Yoshiro Sohma

yoshiros@iuhw.ac.jp

1 Department of Pharmaceutical Sciences and Center for Medical Sciences, International University of Health and Welfare, 2600-1 Kitakanemaru, Otawara, Tochigi 324-8501, Japan

2 Dalton Cardiovascular Research Center, University of Missouri, Columbia, MO 65211, USA

3 Department of Medical Pharmacology and Physiology, University of Missouri, Columbia, MO 65211, USA

4 Department of Human Nutrition, Nagoya University Graduate School of Medicine, Nagoya, Japan

5 Department of Pharmacology, Keio University School of Medicine, Tokyo, Japan
2]. However, there are wide regional and ethnic variations in the spectrum of the CFTR mutations [3, 4]. It is reported that CFTR mutations in Asians are different from those in Caucasians, that is, 55\% of Asian CF patients in UK do not possess any mutation in the routine newborn screening panel [5].

It has been thought that CF is very rare in Japan approximately three per million $[6,7]$. However, definite diagnosis of CF is often difficult for Japanese patients because the sweat $\mathrm{Cl}^{-}$test is not readily available as well as most of the CFTR mutations are of rare types in Japan. This could lead to an underestimation of the prevalence of CF in Japan.

Recently, Nakakuki et al. [8] identified a large heterozygous deletion spanning exons $16,17 \mathrm{a}$, and $17 \mathrm{~b}$ in the CFTR gene of a Japanese CF patient. Following a series of definite genetic diagnosis (sequence of all exons and analysis of genomic rearrangements by multiplex ligation-dependent probe amplification), the 'dele 16-17b' mutation has been found in Japanese CF patients with the highest frequency (13 alleles out of $28 \mathrm{CF}$ alleles inherited from Japanese/Asian ancestry). Importantly, five CF patients (two patients are siblings but the other three patients are non-consanguineous) with homozygous dele 16-17b mutation have already been 
found out of all 103 Japanese CF patients recorded from 1994. The heterozygous large deletion should be easy to escape detection by conventional PCR-based techniques because intact allele masks the deleted allele, which could be the reason why this mutation had not been identified. Thus, it is very important to study the dele 16-17b mutation for understanding unknown CF and CFTR-related diseases in Asians including Japanese.

The dele 16-17b mutation causes a deletion of 153 amino acids from glycine at position 970 (G970) to threonine at 1122 (T1122) in the CFTR protein [ $\Delta(\mathrm{G} 970-\mathrm{T} 1122)$-CFTR] (see Fig. 1 for detail). In the present study, we characterized the $\Delta$ (G970-T1122)-CFTR protein with a combination of imaging and functional assays to understand the molecular defects associated with the $\Delta(\mathrm{G} 970-\mathrm{T} 1122)$ mutation.

\section{Materials and methods}

\section{Preparation of plasmids carrying CFTR variant CDNA}

WT-CFTR and WT-CFTR with C-terminal FLAG tag (C-FLAG-WT-CFTR) constructs inserted into pcDNA3.1/ Zeo(+) plasmids [9-11] were used for the experiments. The massive deletion mutant $\Delta($ G970-T1122)-CFTR was generated from the WT-CFTR templates using the
KOD-Plus-Mutagenesis Kit (TOYOBO Co., Ltd., Osaka, Japan) according to the manufacturer's protocol. The deletion was confirmed by sequencing the inserted cDNA. To express the GFP-fusion CFTR proteins, the CFTR cDNA was inserted into the pEGFP-C1 vector (Clontech Laboratories, Inc., Mountain View, CA, USA) between the restriction enzyme sites of PstI.

\section{Expression of CFTR and its variants in $\mathrm{CHO}$ cells}

CHO cells were maintained in Dulbecco's modified Eagle's medium (D-MEM, Wako Pure Chemical Industries, Osaka, Japan) supplemented with $10 \%$ heat-inactivated fatal bovine serum (FBS) and $100 \mathrm{U} / \mathrm{ml}$ penicillin and $100 \mu \mathrm{g} / \mathrm{ml}$ streptomycin at 37 or $27^{\circ} \mathrm{C}$ in a humidified atmosphere of $5 \% \mathrm{CO}_{2}$ in air. To be transiently expressed CFTR, CHO cells were transfected with CFTR-encoding plasmids using SuperFect transfection reagent (QIAGEN, Hilden, Germany) according to the manufacturer's protocols.

For whole-cell recordings, $\mathrm{CHO}$ cells were co-transfected with CFTR-pcDNA3.1/Zeo(+) plasmids and pEGFP-C3 plasmids (Clontech Laboratories) encoding GFP, and incubated at $27{ }^{\circ} \mathrm{C}$ after transfection for 2-6 days.

A
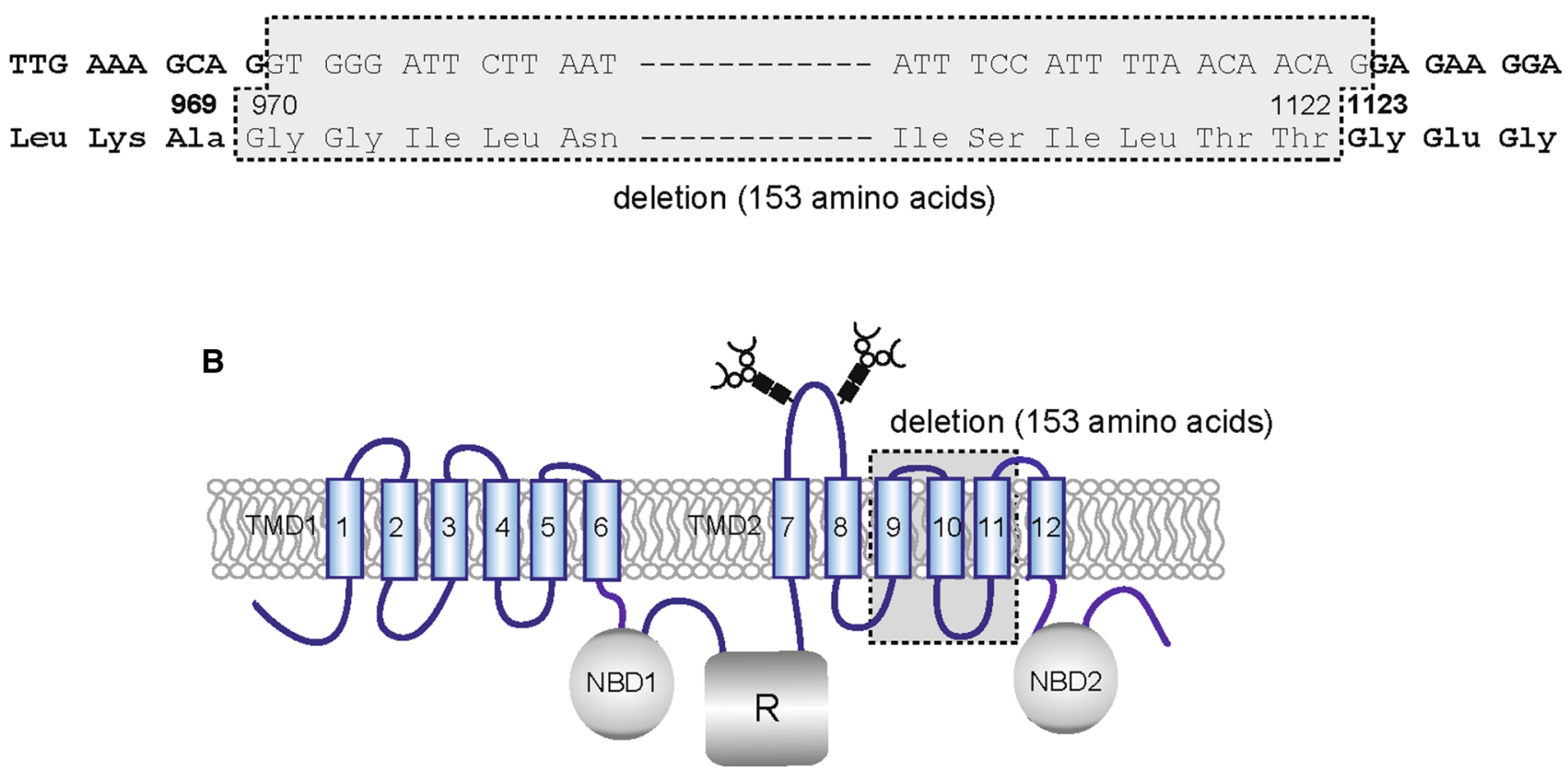

Fig. 1 Schematic illustration of $\Delta($ G970-T1122)-CFTR. a The gene mutation identified most frequently in Japanese CF patients. A massive deletion of 459 base pairs, which results in a deletion of 153 amino acids from glycine at position 970 (G970) to threonine at 1122 (T1122). b Topological location of the deleted region G970-T1122 in the membrane. The amino acid deletion is over three transmembrane helices TM9-TM11. Asn894 and Asn900 on the fourth extracellular loop are consensus sites for $\mathrm{N}$-glycosylation. $N B D$ nucleotide binding domain, $R$ regulatory domain, TMD transmembrane domain 


\section{Immunoblot analysis}

For 24 or 48 h-incubation after transfection, culture medium was removed and the cells were washed with PBS. Cells were harvested with lysis buffer containing $50 \mathrm{mM}$ Tris/ $\mathrm{HCl}(\mathrm{pH} 7.4), 1 \%$ (w/v) Triton X-100, 1 mM dithiothreitol (DTT), and protease inhibitor cocktail (Nacalai Tesque, Inc., Kyoto, Japan). The cell suspension sample was homogenized by passage through a 27 -gauge needle and then centrifuged at $1000 \times g$ for $10 \mathrm{~min}$ at $4{ }^{\circ} \mathrm{C}$. The resulting supernatants were then collected. For deglycosidase treatment, cell lysate samples were incubated with $1 \times$ GlycoBuffer 2 and PNGase F (New England Biolabs, San Leandro, CA, USA) for $10 \mathrm{~min}$ at $37^{\circ} \mathrm{C}$.

Proteins were separated by SDS-PAGE on 7.5 or $10 \%$ polyacrylamide gels and electrophoretically transferred onto polyvinylidene difluoride (PVDF) membranes (BioRad Laboratories, Hercules, CA, USA). Immunoblotting was performed using anti-CFTR antibody (\#2269, Cell Signaling Technology, Danvers, MA, USA), or anti- $\beta$-actin rabbit monoclonal antibody (13E5, Cell Signaling Technology) as the primary antibody, and anti-rabbit IgG-horseradish peroxidase (HRP)-linked antibody (Cell Signaling Technology) as the secondary antibody. HRP-dependent luminescence was developed using Immobilon Western Chemiluminescent HRP substrate (Millipore, Bedford, MA, USA) and detected in an ImageQuant LAS-4000 mini (GE Healthcare, UK Ltd, Buckinghamshire, England).

\section{Immunocytochemistry}

Cells were incubated with CFTR-containing plasmids and SuperFect transfection reagent for $6 \mathrm{~h}$ before they were harvested with $0.05 \%$ trypsin/EDTA solution, seeded onto cell culture dishes with glass bottom (Greiner Bio-One $\mathrm{GmbH}$, Kremsmünster, Austria), and incubated under the above-mentioned culture conditions at $37^{\circ} \mathrm{C}$ for $24 \mathrm{~h}$ or at $27^{\circ} \mathrm{C}$ for $48 \mathrm{~h}$. Cells were washed with PBS and then fixed with 4\% paraformaldehyde in PBS at room temperature for $15 \mathrm{~min}$. Thereafter, cell membranes were permeabilized with $0.1 \%$ Triton $\mathrm{X}-100$ in PBS at room temperature for $10 \mathrm{~min}$, followed by a further incubation with 3\% BSA blocking in PBS at room temperature for $1 \mathrm{~h}$. In some experiments without membrane permeabilization (e.g., Fig. 4a), application of Triton X-100 was omitted. To detect the Golgi apparatus, cells were treated with anti-Golgi $58 \mathrm{~K}$ protein/ formiminotransferase cyclodeaminase antibody (monoclonal 58 K-9, Sigma-Aldrich, St. Louis, MO, USA) as primary antibody, and subsequently with Alexa Fluor 555-conjugated anti-mouse IgG antibody (Thermo Fisher Scientific, Waltham, MA, USA). To detect FLAG-tagged CFTR, cells were treated with anti-FLAG M2 antibody (SigmaAldrich) as primary antibody and subsequently with Alexa
Fluor 555-conjugated anti-rabbit antibody (Thermo Fisher Scientific, Waltham, MA, USA). Cells were finally sealed with cover slips using DAPI Fluoromoun-G (Southern Biotechnology Associates, Birmingham, AL, USA). The immunofluorescence was detected with a super-resolution microscopy (ELYRA OS.1, Carl Zeiss Inc., Oberkochen, Germany).

\section{Whole-cell patch-clamp experiments}

The CFTR currents were recorded at room temperature with an EPC9 amplifier (HEKA Elektronik, Lambrecht/Pfalz, Germany) as described previously $[9,11]$. The bath solution contained $145 \mathrm{mM} \mathrm{NaCl}, 5 \mathrm{mM} \mathrm{KCl}, 2 \mathrm{mM} \mathrm{MgCl}_{2}$, $1 \mathrm{mM} \mathrm{CaCl}_{2}, 5 \mathrm{mM}$ HEPES (pH 7.4 with $\mathrm{NaOH}$ ), $5 \mathrm{mM}$ glucose, and $20 \mathrm{mM}$ sucrose. The pipet solution contained $10 \mathrm{mM}$ EGTA, $10 \mathrm{mM}$ HEPES, $20 \mathrm{mM}$ TEACl, $10 \mathrm{mM}$ MgATP, $2 \mathrm{mM} \mathrm{MgCl}_{2}, 101 \mathrm{mM} \mathrm{CsCl}$, and $5.8 \mathrm{mM}$ glucose. The pipette resistance was $\sim 5 \mathrm{M} \Omega$ in the bath solution. To monitor the CFTR currents, the membrane potential was held at $0 \mathrm{mV}$ and a 1 -s voltage ramp $(-100$ to $+100 \mathrm{mV})$ was applied every $6 \mathrm{~s}$. Currents were filtered at $1 \mathrm{kHz}$ with a built-in 4-pole Bessel filter, and digitized by the computer at a sampling rate of $2 \mathrm{kHz}$. CFTR was activated with $10 \mu \mathrm{M}$ forskolin and inhibited by $5 \mu \mathrm{M}$ CFTRinh-172. The net current was calculated as the current between -100 and $+100 \mathrm{mV}$ minus the basal current (leak current) at the same voltages, using Igor software (Wavemetrics, Lake Oswego, OR) or Clampfit software (Axon). Current-voltage $(I-V)$ relationships were obtained when whole-cell currents reached a steady state under each condition.

\section{Chemicals}

VX-809 was purchased from ChemScene, LCC (Monmouth Junction, NJ, USA). Forskolin (FSK) was purchased from Alexis Corporation (Läufelfingen, Switzerland), and CFTRinh-172(4-[[4-oxo-2-thioxo-3-[3-(trifluoromethyl) phenyl]-5-thiazolidinylidene]methyl]-benzoic acid) was kindly provided by Dr. Robert Bridges with support from the Cystic Fibrosis Foundation Therapeutics.

\section{Results}

\section{$\Delta$ (G970-T1122)-mutant CFTR proteins}

The 'dele 16-17b' gene mutation identified in Japanese CF patients with the highest frequency [6], leads to a deletion of 459 base pairs from 2909G to $3367 \mathrm{G}$ in CFTR cDNA (Fig. 1a) [8]. This massive gene deletion results in a deletion of 153 amino acids from glycine at position 970 (G970) to threonine at 1122 (T1122) without frameshift in the CFTR 
protein $[\Delta($ G970-T1122)-CFTR] (Fig. 1a). The amino acid deletion is located over three transmembrane helices TM9-TM11 (Fig. 1b). However, the amino acid sequences including TM12 and NBD2 are intact because no frameshift is induced by the deletion. Note that the fourth extracellular loop between TM7 and TM 8 containing two N-glycosylation sites, Asn894 and Asn900 [12, 13], is retained in the mutant construct. In WT-CFTR, the newly synthesized CFTR protein undergoes core glycosylation at these $\mathrm{N}$-glycosylation sites in the endoplasmic reticulum (ER) and further complex-type glycan attachment upon traversing the Golgi apparatus $[14,15]$.

\section{$\Delta$ (G970-T1122)-CFTR proteins mainly expressed as immature forms}

In order to investigate the influence of the dele $16-17 \mathrm{~b}$ mutation on CFTR protein expression, we transiently expressed $\Delta$ (G970-T1122)-CFTR in CHO cells and performed immunoblotting using the anti-CFTR antibody.

WT-CFTR protein is known to be detected around $180-200 \mathrm{kDa}$ (mature band) because of two oligosaccharide chains of the N-glycosylation at Asn894 and Asn900 [12, 13], whereas theoretical molecular mass of WT-CFTR protein is about $168 \mathrm{kDa}$. At $37^{\circ} \mathrm{C}$, WT-CFTR proteins showed two bands around $170 \mathrm{kDa}$ (core-glycosylated immature $\mathrm{B}$ band) as well as $200 \mathrm{kDa}$ (complex-glycosylated mature $\mathrm{C}$ band) (left panel in Fig. 2a) [16]. A PNGase F treatment, which cleaves $\mathrm{N}$-linked oligosaccharide chains from proteins, shifted both two WT-CFTR bands to around $160 \mathrm{kDa}$, presumably corresponding to non-glycosylated WT-CFTR.

$\Delta$ F508-CFTR proteins, due to defective folding, were mainly detected as the immature $\mathrm{B}$ band (center panel in Fig. 2a). The PNGase F treatment also shifted the $\Delta \mathrm{F} 508$ CFTR band to a little but significantly lower molecular weight (center panel in Fig. 2a), consistent with that the $\Delta$ F508-CFTR protein is core-glycosylated (immature glycosylation) $[14,17]$.

$\Delta$ (G970-T1122)-CFTR proteins were mainly detected around $140 \mathrm{kDa}$, which was consistent with the deletion of 153 amino acids from WT-CFTR. Interestingly, like the $\Delta$ F508 mutation, the $\Delta(\mathrm{G} 970-\mathrm{T} 1122)$-CFTR proteins were only shifted to a lower molecular weight band slightly by the PNGase F treatment (right panel in Fig. 2a). This suggested that $\Delta$ (G970-T1122)-CFTR proteins were mainly expressed in the immature core-glycosylated form.

\section{Effect of VX-809 on the CFTR protein expression}

VX-809 (Lumacaftor), known as a CFTR corrector, acts as a chemical chaperone for CFTR with the processing defect to restore the cell-surface expression of CFTR mutant proteins [18]. Incubations with VX-809 increased the mature form of $\Delta$ F508-CFTR proteins in a concentration-dependent manner. This effect was also more predominant when cells were incubated at a lower temperature of $27{ }^{\circ} \mathrm{C}$ (center panels
Fig. 2 Effect of VX-809 on maturation of $\Delta(\mathrm{G} 970-\mathrm{T} 1122)$ CFTR protein. Immunoblots for WT-, $\Delta$ F508-, and $\Delta$ (G970-T1122)-CFTR proteins expressed in $\mathrm{CHO}$ cells in the presence of 0,3 , or $10 \mu \mathrm{M} \mathrm{VX}-809$ at a $37^{\circ} \mathrm{C}$ for $24 \mathrm{~h}$ or b $27^{\circ} \mathrm{C}$ for $48 \mathrm{~h}$. Cell lysate samples were analyzed by immunoblotting with the anti-CFTR rabbit polyclonal antibody described in the Materials and methods section. $\beta$-actin was used as an internal loading control. Open arrowheads, non-glycosylated CFTR by PNGase F; gray arrowheads, immature glycosylated CFTR; closed arrowheads, mature glycosylated CFTR
A $\underline{37^{\circ} \mathrm{C}}$

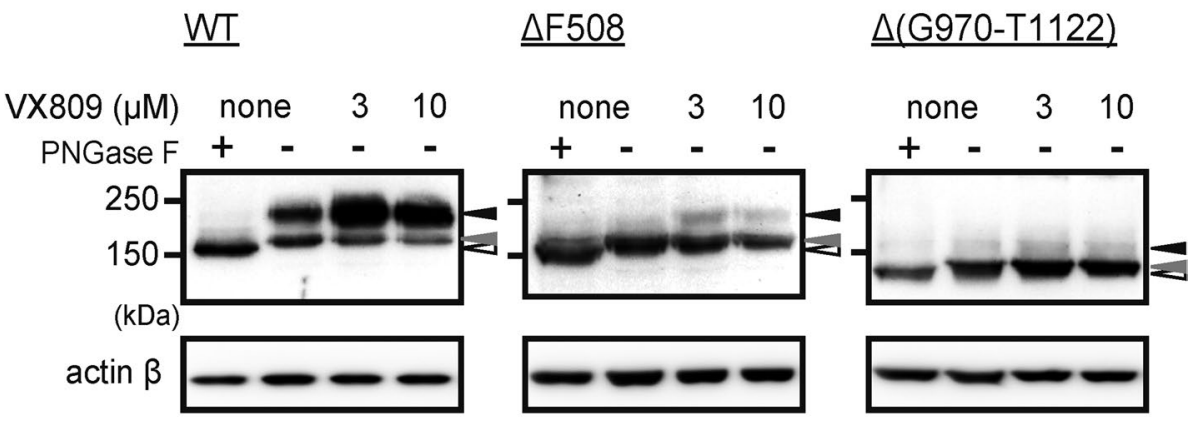

B $\underline{27^{\circ} \mathrm{C}}$

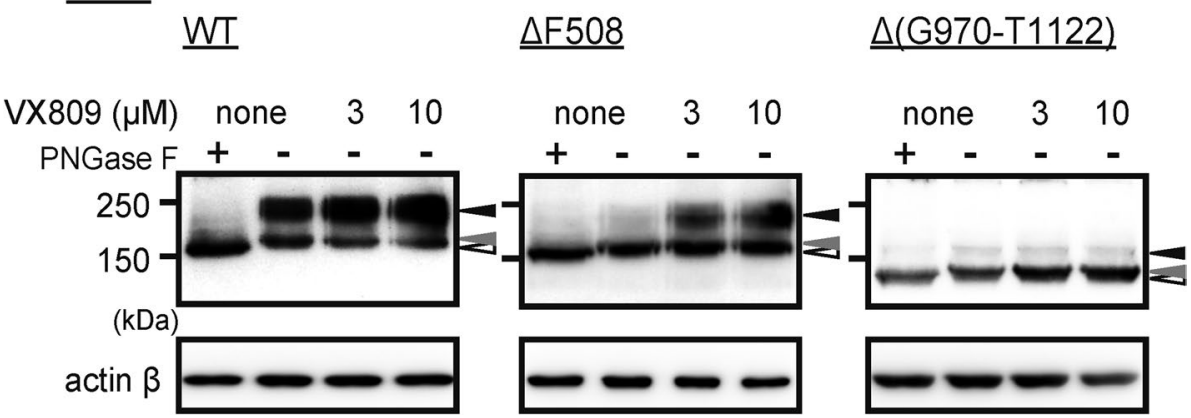


in Fig. 2a, b), probably because incubation at $27^{\circ} \mathrm{C}$ promoted thermodynamic stability of the mutant CFTR [19], and subsequently enhanced the effects of VX-809 [20]. In contrast, the expression pattern of $\Delta(\mathrm{G} 970-\mathrm{T} 1122)$-CFTR proteins was not significantly affected by the VX-809 treatment: the mature forms were still extremely low at both 37 and $27{ }^{\circ} \mathrm{C}$ (right panels in Fig. 2a, b). These results indicate that the corrector VX-809 fails to help the maturation of $\Delta$ (G970-T1122)-CFTR.

\section{$\Delta$ (G970-T1122)-CFTR proteins localized in the intercellular compartment}

To investigate the intercellular processing of $\Delta(\mathrm{G} 970$ T1122)-CFTR proteins in more detail, we performed immunocytochemical analysis using the super-resolution microscopy. Figure 3 depicts the immunofluorescence images of $\mathrm{CHO}$ cells expressing $\mathrm{N}$-terminal GFP-tagged WT-, $\Delta$ F508-, and $\Delta$ (G970-T1122)-CFTR incubated at 37 or $27{ }^{\circ} \mathrm{C} 48 \mathrm{~h}$ after the corresponding constructs were transiently transfected into the cells. The GFP signal can be clearly detected in the plasma membrane as well as in the intracellular compartments in GFP-WT-CFTR-expressing cells (left panels in Fig. 3), which was not affected by the low temperature $27^{\circ} \mathrm{C}$ or the VX-809 treatment.

GFP- $\Delta$ F508-CFTR proteins were only detected in the intracellular compartment at $37^{\circ} \mathrm{C}$ (center/top panel in Fig. 3). However, its expression in the plasma membrane was detected with the combination of the low temperature rescue and the VX-809 treatment (center/bottom panel in Fig. 3), but not discernibly by the low temperature alone (center/middle panel in Fig. 3).

In the case of GFP- $\Delta$ (G970-T1122)-CFTR, quite strong GFP signals were distributed over the intracellular compartment; however, little signal was detected in the plasma membrane at $27^{\circ} \mathrm{C}$ as well as $37^{\circ} \mathrm{C}$. Even the combination of the low temperature and the VX-809 treatment failed to make a plasma membrane expression pattern for the $\Delta$ (G970-T1122)-CFTR (right/bottom panel in Fig. 3).

Taking the immunoblotting data (Fig. 2) and the immunocytochemical data (Fig. 3) together, we conclude that $\Delta$ (G970-T1122)-CFTR is synthesized but not trafficked to the plasma membrane. Therefore, the $\Delta(\mathrm{G} 970-\mathrm{T} 1122)$ mutation can be categorized into the class II mutation like $\Delta$ F508.
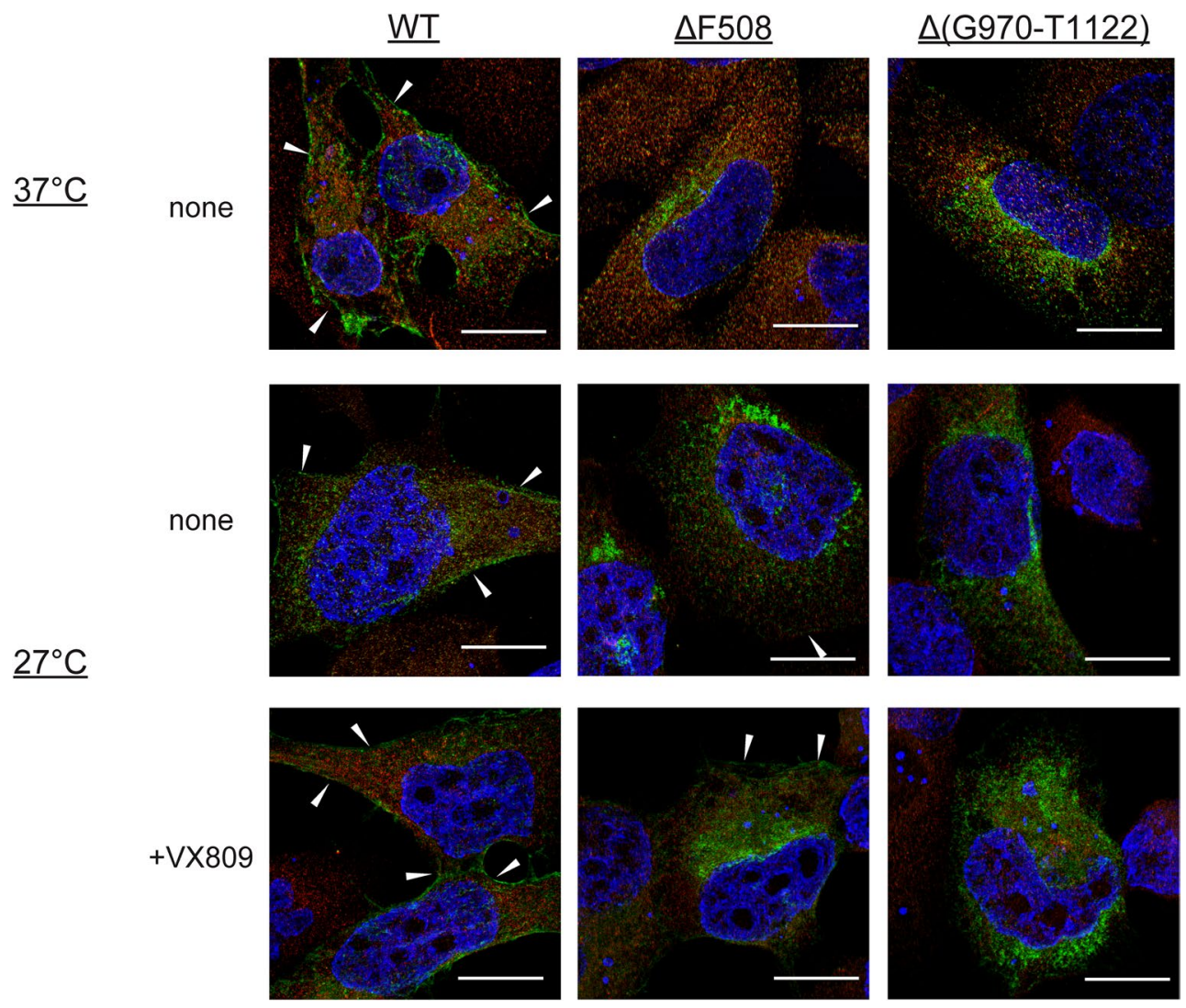

Fig. 3 Localization of $\Delta$ (G970-T1122)-CFTR protein. Super-resolution microscopic images for WT-, $\Delta \mathrm{F} 508-$, and $\Delta$ (G970-T1122)CFTR expressed in $\mathrm{CHO}$ cells incubated at $37{ }^{\circ} \mathrm{C}$ for $24 \mathrm{~h}$ and with

or without $10 \mu \mathrm{M}$ VX-809 at $27{ }^{\circ} \mathrm{C}$ for $48 \mathrm{~h}$. Green, GFP-tagged CFTR proteins; blue, nuclei (DAPI); red, Golgi apparatus. Scale bars $10 \mu \mathrm{m}$ (color figure online) 


\section{The C-terminal FLAG tag affects $\Delta$ (G970-T1122)-CFTR expression}

Surprisingly, we found that C-terminal FLAG tag changed the expression manner of $\Delta(\mathrm{G} 970-\mathrm{T} 1122)-\mathrm{CFTR}$ proteins. Figure 4a depicts that immunoblots of WT- and $\Delta(\mathrm{G} 970$ T1122)-CFTR proteins with or without C-terminal FLAG tag.

The signal intensity ratio between mature and immature forms of WT-CFTR proteins was little affected by the C-terminal FLAG tag. In contrast, the C-terminal FLAG tag clearly increased the signal intensity of the mature form in $\Delta$ (G970-T1122)-CFTR proteins (Fig. 4a). Figure 4b summarizes the relative expression levels of mature WTand $\Delta$ (G970-T1122)-CFTR proteins with and without the C-terminal FLAG. Although the underlying mechanism for this effect of the C-terminal FLAG tag on the maturation of $\Delta$ (G970-T1122)-CFTR proteins is unknown, this observation does suggest that the C-terminal FLAG tag can be used as a tool for further studies of this unusual CFTR mutant.
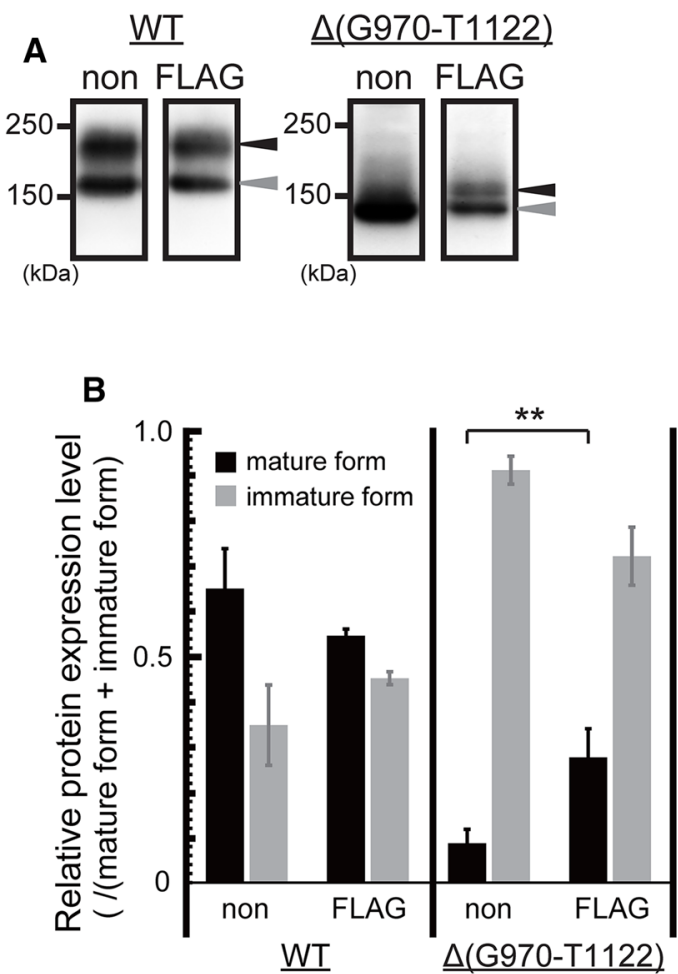

Fig. 4 Effects of the C-terminal FLAG tag on expression of $\Delta(\mathrm{G} 970$ T1122)-CFTR proteins. a Immunoblots for WT- and $\Delta$ (G970-T1122)CFTR with or without C-terminal FLAG tag. The black and gray arrowheads indicate mature and immature forms of CFTR proteins. Cells were incubated at $27^{\circ} \mathrm{C}$ for $48 \mathrm{~h}$ after transfection. b Summary for the immunoblot signal intensity of immature (grey) and mature (black) forms of WT- and $\Delta(\mathrm{G} 970-\mathrm{T} 1122)$-CFTR proteins. Data were normalized to the total signal intensity and expressed as relative pro-

\section{C-terminal regions of $\Delta$ (G970-T1122)-CFTR proteins might be located at the intracellular side of the plasma membrane}

According to the membrane topology of CFTR, the C-terminal region including NBD2 of $\Delta($ G970-T1122)-CFTR could be located in the extracellular space because an odd number (three) of transmembrane helices (TM 9-10) were lost in TMD2 of $\Delta$ (G970-T1122)-CFTR (Fig. 1b). To investigate this possibility, we performed immunostaining experiments to localize the C-terminus of the C-FLAG- $\Delta$ (G970-T1122)CFTR using anti-FLAG antibody.

As demonstrated in Fig. 4c, C-terminal FLAG-tagged WT- and $\Delta$ (G970-T1122)-CFTR proteins were probed with the anti-FLAG antibody and then labeled with red fluorescence dye (Alexa Fluor 555) under permeabilized or nonpermeabilized condition.

C-FLAG-tagged WT-CFTR proteins were clearly detected both in the plasma membrane and in the intracellular compartments under the permeabilized condition.

C

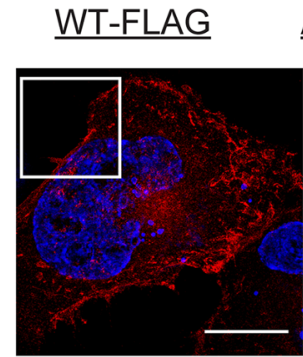

$\triangle(\mathrm{G} 970-\mathrm{T} 1122)-\mathrm{FLAG}$
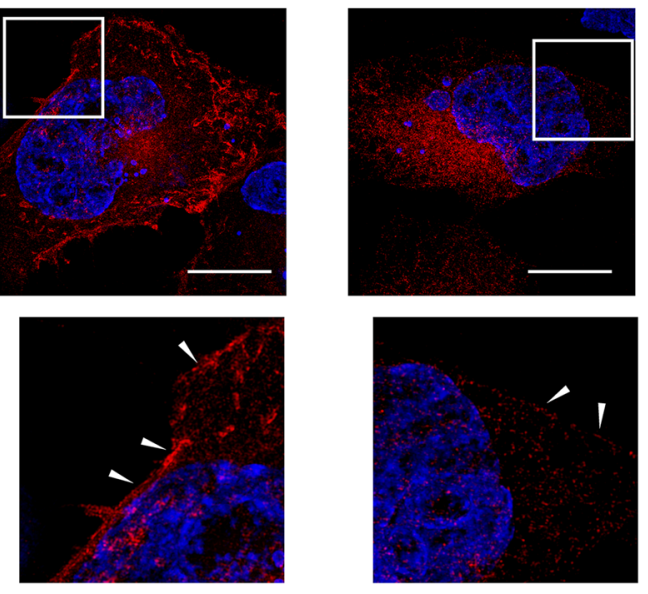

non-P
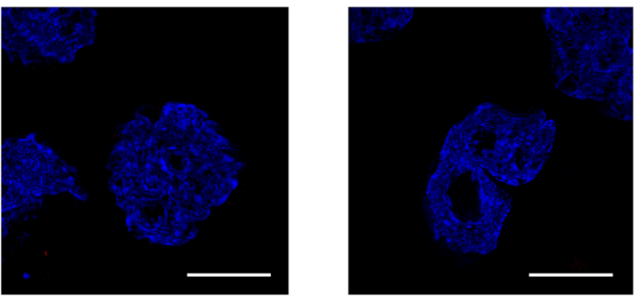

tein expression levels. Mean value \pm SD from triplicate experiments. Statistical significance $\left(^{*}, p<0.01\right)$ was evaluated by Student's $t$ test. c Immunocytochemical staining of $\mathrm{CHO}$ cells transiently expressing C-terminal FLAG-tagged WT- and $\Delta$ (G970-T1122)-CFTR proteins with $(\mathrm{P})$ or without (non-P) membrane permeabilization. Red, FLAGtagged CFTR proteins stained with Alexa Fluor 555-linked antiFLAG antibody; blue, nuclei (DAPI). Scale bar $10 \mu \mathrm{m}$. Cells were incubated at $27^{\circ} \mathrm{C}$ for $48 \mathrm{~h}$ after transfection (color figure online) 
However, the red fluorescence signal was completely abolished under the non-permeabilized condition (left/bottom panel in Fig. 4c). This suggests that the C-terminal region of WT-CFTR is located inside the cell membrane.

In the case of the C-FLAG-tagged $\Delta$ (G970-T1122)CFTR, a line of red fluorescence signal dots was detected along the putative plasma membrane (right/top and middle panels in Fig. 4c), but much more mutant proteins were detected in the intracellular compartments. In the non-permeabilized cells (right/bottom panel in Fig. 4c), the red fluorescence was completely abolished just like in the C-FLAGWT-CFTR-expressing cells.

Similar results were obtained by cell surface biotinylation assays. That is, the anti-FLAG antibody failed to capture C-FLAG- $\Delta$ (G970-T1122)-CFTR proteins possibly expressed on the cell surface (data not shown) although it might be due to its low expression density.

These results support the idea that the $\mathrm{C}$-terminal region of the C-FLAG- $\Delta$ (G970-T1122)-CFTR protein is surprisingly located inside the plasma membrane.

\section{C-terminal FLAG-tagged $\Delta$ (G970-T1122)-CFTR proteins have no channel activities}

Finally we investigated the channel function of the C-FLAG$\Delta$ (G970-T1122)-CFTR presumably expressed in the plasma membrane. As shown in Fig. 5, $10 \mu \mathrm{M}$ forskolin failed to induce whole-cell currents in the cells expressing the C-FLAG- $\Delta$ (G970-T1122)-CFTR as well as the $\Delta$ (G970T1122)-CFTR, whereas it constantly induced large wholecell currents of nanoampere magnitude for both WT- and C-FLAG-WT-CFTR. However, a large degree of cell-to-cell variation of whole-cell CFTR current amplitudes in our transient expression system is noted. Thus, even if the C-FLAG$\Delta$ (G970-T1122)-CFTR can be expressed in the plasma membrane, no detectable chloride channel activity is seen.

\section{Discussion}

In the present study, we characterized $\Delta$ (G970-T1122)CFTR, the most frequent CFTR mutant identified in Japanese cystic fibrosis patients. We conclude that $\Delta$ (G970T1122)-CFTR can be categorized into a class II mutation, like $\Delta$ F508 mutation, but VX-809 could not rescue the trafficking defect of $\Delta$ (G970-T1122)-CFTR (Figs. 2, 3). In addition, considering the drastic deletion of three transmembrane segments that likely participate in the construction of the anion permeation pathway [21,22], we propose that the mutant protein is non-functional as the electrophysiological experiments also imply.
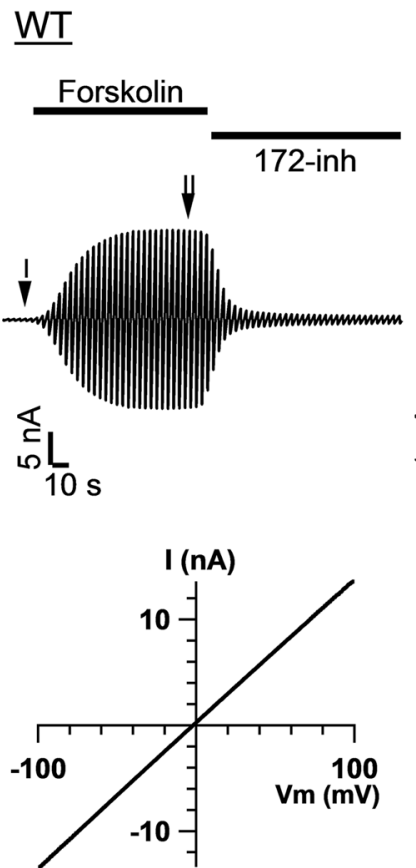

WT-FLAG
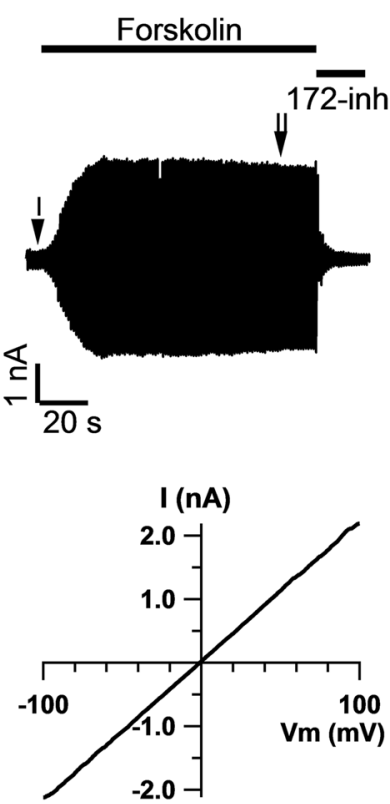

$\underline{\Delta(\mathrm{G} 970-\mathrm{T} 1122)}$
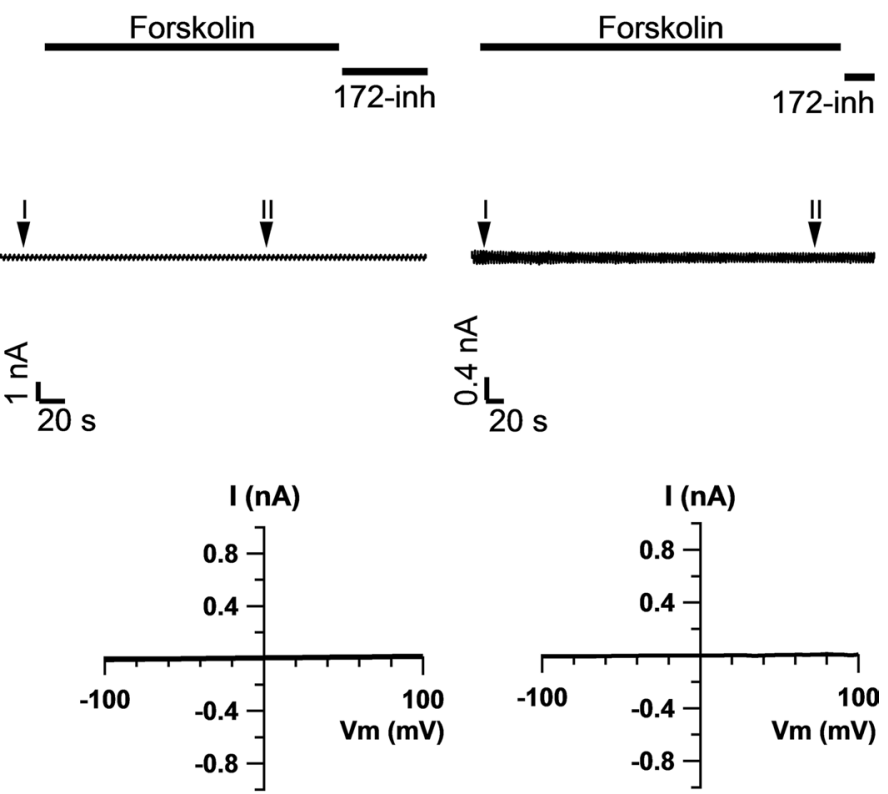

forskolin, and $5 \mu \mathrm{M}$ CFTRinh-172 (inh-172) was subsequently applied to confirm the CFTR currents. The lower panel shows the $I-V$ relationships of forskolin-induced conductance by subtracting the leak currents at position I from the overall current at position II. Each group represents the average of five data points 


\section{No effects of VX-809 on the trafficking defect of $\Delta$ (G970-T1122)-CFTR}

CFTR molecule contains two TMDs with four intracellular loops (ICL1-4), two NBDs, and a regulatory domain [13]. These domains interact with each other for the structural and functional integrity of the channel. The $\Delta$ F508 mutation in NBD1 caused structural instability at the interfaces between ICL1 in TMD1, ICL4 in TMD2, and NBD1, so that $\Delta$ F508-CFTR proteins fail to fold properly and do not efficiently traffic to the plasma membrane [23, 24]. A previous report suggested that corrector VX-809 stabilizes the NBD1TMD1/TMD2 interface to rescue the defective protein folding mutant (e.g., $\Delta$ F508) CFTR proteins [25]. Recently, it was proposed that $\mathrm{VX}-809$ binds to TMD1 to repair folding and processing defects of CFTR by promoting interactions between ICL1 and NBD1 [26].

Unfortunately, VX-809 was not effective for the $\Delta(\mathrm{G} 970$ T1122)-CFTR (Figs. 2, 3). In $\Delta$ (G970-T1122)-CFTR proteins, the middle half of TMD2 including ICL4 is lost (Fig. 1b), leading to the lack of the NBD1-CL4 interface in $\Delta$ (G970-T1122)-CFTR. Although we do not know the reason why VX-809 does not help the maturation of $\Delta(\mathrm{G} 970$ T1122)-CFTR, it should be noted that the $\Delta$ F508 mutant proteins retain some channel function, but $\Delta(\mathrm{G} 970-\mathrm{T} 1122)-$ CFTR does not.

\section{C-terminal FLAG tag partially rescued $\Delta$ (G970-T1122)-CFTR}

We found that C-terminal FLAG tag increased the mature band of $\Delta$ (G970-T1122)-CFTR in the immunoblot analysis (Fig. 4a, b). A simple interpretation of this finding is that the C-terminal FLAG tag promotes maturation of the $\Delta(\mathrm{G} 970$ T1122)-CFTR proteins. Several previous studies have investigated the importance of the $\mathrm{C}$-terminal region that influences the localization, protein stability, and function of CFTR. The PSD-95/discs-large/ZO-1 (PDZ) binding motif is the most relevant region of the CFTR C-terminus, which has been demonstrated to interact with the PDZ domain proteins including $\mathrm{Na}^{+} / \mathrm{H}^{+}$-exchanger regulatory factor isoform-1 (NHERF-1; also known as EBP50, ezrin/radixin/moesinbinding protein 50), NHERF2, NHERF3 (also known as CAP70, CFTR-associated protein 70), NHREF4, and CFTRassociated ligand (CAL) [27-29]. NHERF-1 could tether CFTR to cortical cytoskeletal elements via binding to ezrin in a phosphorylation-dependent manner as well as with other membrane proteins [30, 31]. An anchoring of CFTR to cytoskeleton could potentially make it possible to stabilize CFTR proteins in the plasma membrane and it has been suggested that the interaction with either NHERF or CAP70 might increase the channel activity of CFTR [32-34]. On the other hand, interaction with CAL causes the inhibitory effect of CFTR localization on the cell surface: the binding of CAL retains CFTR within the cell and targets CFTR for degradation [35]. Furthermore, a sequence upstream of the PDZ binding motif within CFTR C-terminus also enhances the interaction with the PDZ domain proteins [36]. Other C-terminal regions also play pivotal roles in the CFTR protein lifetime. Some motifs on the C-terminus, e.g., tyrosine-based internalization motif and di-leucine-based motif, are related to CFTR endocytosis, and C-terminal truncations enhances its proteasome-dependent degradation [37]. Therefore, the C-terminus FLAG tag may interfere with the interactions of $\Delta$ (G970-T1122)-CFTR with many of the above-described binding proteins.

It is also worth noting that the C-terminal FLAG taginduced band shift (molecular weight shift) in $\Delta$ (G970T1122)-CFTR was smaller than the maturation-included band shift in WT-CFTR (Fig. 4a). Although the exact reason for this difference is unclear, one possibility is that the complex-glycosylation of $\Delta$ (G970-T1122)-CFTR was not as extensive as that of WT-CFTR [38].

Further studies are needed to elucidate the mechanism of $\Delta$ (G970-T1122)-mutation induced trafficking defect as well as its rescue by the C-terminal FLAG tag.

\section{Clinical impacts of $\Delta($ G970-T1122)-CFTR}

The dele 16-17b gene mutation has been found in Japanese CF patients with the highest frequency (13 alleles out of 28 CF alleles of Japanese/Asian ancestry completely-analyzed), that is, about $70 \%$ of Japanese CF patients have the dele 16-17b gene mutation. On the other hand, the Cystic Fibrosis Mutation Database (www.genet.sickkids.on.ca/cftr) includes 39 different genomic rearrangements accounting for only $1-3 \%$ of the CFTR mutations in Caucasians [39].

Note that five homozygous dele $16-17 \mathrm{~b}$ patients have already been found in Japanese CF patients. Two of them are siblings (a 4-year-old girl and a 2-year-old boy), who share an identical genotype. However, importantly, the elder sister shows mild bronchitis whereas the younger brother shows a severe phenotype with pancreatic insufficiency (clinical data not shown). This suggests that pathogenesis of CF caused by $\Delta(\mathrm{G} 970-\mathrm{T} 1122)$ mutation could be more complicated and other modifier genes may be important. Also, the homozygote patients with little CF symptoms suggest a possible underestimation of the population with the dele 16-17b gene mutation in Japan where no systematic CF screening is available. Historically, the first report of the dele 16-17b gene mutation was from a French CF patient whose healthy mother originated from South Korea [40], suggesting that the dele16-17b mutation might be unique to Asian CF. Further study of the $\Delta$ (G970-T1122)-CFTR is essential for comprehensively understanding CF and CFTR-related diseases in Japanese/Asian populations. 


\section{Conclusions}

The most frequent disease-associated mutation in Japanese CF patients, dele $16-17 \mathrm{~b}$, produces a class II mutant $\Delta$ (G970-T1122)-CFTR. Interestingly, a C-terminal FLAG tag partially rescues $\Delta($ G970-T1122)-CFTR whereas lumacaftor (VX-809), a US FDA-approved class II mutant CFTR corrector, is of little help. In addition, even when $\Delta$ (G970-T1122)-CFTR proteins reach the cell membrane, it is unlikely for them to carry out the function of cAMPregulated chloride channel or respond to CFTR potentiators. Although current advancements in developing pharmaceutical reagents for the treatment of patients with $\mathrm{CF}$ have benefited a significant numbers of patients, it remains an overbearing challenge to overcome defects caused by some mutations such as $\Delta(\mathrm{G} 970-\mathrm{T} 1122)$.

Acknowledgements We are grateful to Drs. Yoichiro Abe and Masato Yasui (Keio University) for their useful help and discussions. We are also grateful to the Collaborative Research Resources, Keio University School of Medicine for equipment and technical supports. K.W.-N. is a Japan Society for the Promotion of Sciences (JSPS) Research Fellow. This work was supported by JSPS KAKENHI Grant Numbers 17J40033 (K.W.-N.), 25293049, 15K15035, 16H05122 (Y.S.), and 16K09392 (H.I.).

Author contributions KW-N designed and performed the molecular biological and biochemical experiments and helped write the manuscript. Y-CY designed and performed the electro-physiological experiments and helped write the manuscript. $\mathrm{MN}$ designed the molecular biological experiments and T-CH designed the electro-physiological experiments. HI conceptualized the project and helped write the manuscript. YS conceptualized the project, designed the experiments, and helped write the manuscript.

\section{Compliance with ethical standards}

Conflict of interest The authors declare that they have no conflicts of interest.

Ethical approval This article does not contain any studies with human participants or animals performed by any of the authors.

\section{References}

1. Welsh MJ, Smith AE (1993) Molecular mechanisms of CFTR chloride channel dysfunction in cystic fibrosis. Cell 73(7):12511254. http://www.ncbi.nlm.nih.gov/pubmed/7686820

2. Sohma Y, Hwang TC (2015) Cystic fibrosis and the CFTR anion channel. In: Zheng J, Trudeau MC (eds) Handbook of ion channels. CRC Press, Taylor \& Francis Books Inc, Oxford, pp 627-648

3. Zielenski J, Tsui LC (1995) Cystic fibrosis: genotypic and phenotypic variations. Annu Rev Genet 29:777-807. https://doi. org/10.1146/annurev.ge.29.120195.004021

4. Singh M, Rebordosa C, Bernholz J, Sharma N (2015) Epidemiology and genetics of cystic fibrosis in Asia: in preparation for the next-generation treatments. Respirology 20(8):1172-1181. https ://doi.org/10.1111/resp.12656

5. Bosch B, Bilton D, Sosnay P, Raraigh KS, Mak DY, Ishiguro H, Gulmans V, Thomas M, Cuppens H, Amaral M, De Boeck K (2017) Ethnicity impacts the cystic fibrosis diagnosis: a note of caution. J Cyst Fibros. https://doi.org/10.1016/j.jcf.2017.01.016

6. Imaizumi $Y$ (1995) Incidence and mortality rates of cystic fibrosis in Japan, 1969-1992. Am J Med Genet 58(2):161-168. https://doi. org/10.1002/ajmg.1320580215

7. Yamashiro Y, Shimizu T, Oguchi S, Shioya T, Nagata S, Ohtsuka Y (1997) The estimated incidence of cystic fibrosis in Japan. J Pediatr Gastroenterol Nutr 24(5):544-547. http://www.ncbi.nlm. nih.gov/pubmed/9161949

8. Nakakuki M, Fujiki K, Yamamoto A, Ko SB, Yi L, Ishiguro M, Yamaguchi M, Kondo S, Maruyama S, Yanagimoto K, Naruse S, Ishiguro H (2012) Detection of a large heterozygous deletion and a splicing defect in the CFTR transcripts from nasal swab of a Japanese case of cystic fibrosis. J Hum Genet 57(7):427-433. https://doi.org/10.1038/jhg.2012.46

9. Yu YC, Miki H, Nakamura Y, Hanyuda A, Matsuzaki Y, Abe Y, Yasui M, Tanaka K, Hwang TC, Bompadre SG, Sohma Y (2011) Curcumin and genistein additively potentiate G551DCFTR. J Cyst Fibros 10(4):243-252. https://doi.org/10.1016/j. jcf.2011.03.001

10. Mio K, Ogura T, Mio M, Shimizu H, Hwang TC, Sato C, Sohma Y (2008) Three-dimensional reconstruction of human cystic fibrosis transmembrane conductance regulator chloride channel revealed an ellipsoidal structure with orifices beneath the putative transmembrane domain. J Biol Chem 283(44):30300-30310. https ://doi.org/10.1074/jbc.M803185200

11. Shimizu H, Yu YC, Kono K, Kubota T, Yasui M, Li M, Hwang TC, Sohma Y (2010) A stable ATP binding to the nucleotide binding domain is important for reliable gating cycle in an $\mathrm{ABC}$ transporter CFTR. J Physiol Sci 60(5):353-362. https://doi. org/10.1007/s12576-010-0102-2

12. Chang XB, Mengos A, Hou YX, Cui L, Jensen TJ, Aleksandrov A, Riordan JR, Gentzsch M (2008) Role of N-linked oligosaccharides in the biosynthetic processing of the cystic fibrosis membrane conductance regulator. J Cell Sci 121(Pt 17):2814-2823. https:// doi.org/10.1242/jcs.028951

13. Riordan JR, Rommens JM, Kerem B, Alon N, Rozmahel R, Grzelczak Z, Zielenski J, Lok S, Plavsic N, Chou JL et al (1989) Identification of the cystic fibrosis gene: cloning and characterization of complementary DNA. Science 245(4922):1066-1073. http:// www.ncbi.nlm.nih.gov/pubmed/2475911

14. Cheng SH, Gregory RJ, Marshall J, Paul S, Souza DW, White GA, O'Riordan CR, Smith AE (1990) Defective intracellular transport and processing of CFTR is the molecular basis of most cystic fibrosis. Cell 63(4):827-834. http://www.ncbi.nlm.nih.gov/pubme d/1699669

15. Lukacs GL, Mohamed A, Kartner N, Chang XB, Riordan JR, Grinstein S (1994) Conformational maturation of CFTR but not its mutant counterpart $(\triangle \mathrm{F} 508)$ occurs in the endoplasmic reticulum and requires ATP. EMBO J 13(24):6076-6086. http://www.ncbi. nlm.nih.gov/pubmed/7529176

16. Glozman R, Okiyoneda T, Mulvihill CM, Rini JM, Barriere H, Lukacs GL (2009) N-glycans are direct determinants of CFTR folding and stability in secretory and endocytic membrane traffic. J Cell Biol 184(6):847-862. https://doi.org/10.1083/jcb.20080 8124

17. Kartner N, Augustinas O, Jensen TJ, Naismith AL, Riordan JR (1992) Mislocalization of $\triangle F 508$ CFTR in cystic fibrosis sweat gland. Nat Genet 1(5):321-327. https://doi.org/10.1038/ng089 2-321

18. Van Goor F, Hadida S, Grootenhuis PD, Burton B, Stack JH, Straley KS, Decker CJ, Miller M, McCartney J, Olson ER, Wine 
JJ, Frizzell RA, Ashlock M, Negulescu PA (2011) Correction of the F508del-CFTR protein processing defect in vitro by the investigational drug VX-809. Proc Natl Acad Sci USA 108(46):1884318848. https://doi.org/10.1073/pnas. 1105787108

19. Denning GM, Anderson MP, Amara JF, Marshall J, Smith AE, Welsh MJ (1992) Processing of mutant cystic fibrosis transmembrane conductance regulator is temperature-sensitive. Nature 358(6389):761-764. https://doi.org/10.1038/358761a0

20. He L, Kota P, Aleksandrov AA, Cui L, Jensen T, Dokholyan NV, Riordan JR (2013) Correctors of $\triangle$ F508 CFTR restore global conformational maturation without thermally stabilizing the mutant protein. FASEB J 27(2):536-545. https://doi.org/10.1096/fj.12216119

21. Rubaiy HN, Linsdell P (2015) Location of a permeant anion binding site in the cystic fibrosis transmembrane conductance regulator chloride channel pore. J Physiol Sci 65(3):233-241. https:// doi.org/10.1007/s12576-015-0359-6

22. Hwang TC, Yeh JT, Zhang J, Yu YC, Yeh HI, Destefano S (2018) Structural mechanisms of CFTR function and dysfunction. J Gen Physiol 150(4):539-570. https://doi.org/10.1085/jgp.201711946

23. Rabeh WM, Bossard F, Xu H, Okiyoneda T, Bagdany M, Mulvihill CM, Du K, di Bernardo S, Liu Y, Konermann L, Roldan A, Lukacs GL (2012) Correction of both NBD1 energetics and domain interface is required to restore $\triangle \mathrm{F} 508$ CFTR folding and function. Cell 148(1-2):150-163. https://doi.org/10.1016/j. cell.2011.11.024

24. Mendoza JL, Schmidt A, Li Q, Nuvaga E, Barrett T, Bridges RJ, Feranchak AP, Brautigam CA, Thomas PJ (2012) Requirements for efficient correction of $\triangle \mathrm{F} 508$ CFTR revealed by analyses of evolved sequences. Cell 148(1-2):164-174. https://doi. org/10.1016/j.cell.2011.11.023

25. Okiyoneda T, Veit G, Dekkers JF, Bagdany M, Soya N, Xu H, Roldan A, Verkman AS, Kurth M, Simon A, Hegedus T, Beekman JM, Lukacs GL (2013) Mechanism-based corrector combination restores $\triangle F 508$-CFTR folding and function. Nat Chem Biol 9(7):444-454. https://doi.org/10.1038/nchembio.1253

26. Loo TW, Clarke DM (2017) Corrector VX-809 promotes interactions between cytoplasmic loop one and the first nucleotidebinding domain of CFTR. Biochem Pharmacol. https://doi. org/10.1016/j.bcp.2017.03.020

27. Hall RA, Ostedgaard LS, Premont RT, Blitzer JT, Rahman N, Welsh MJ, Lefkowitz RJ (1998) A C-terminal motif found in the beta2-adrenergic receptor, $\mathrm{P} 2 \mathrm{Y} 1$ receptor and cystic fibrosis transmembrane conductance regulator determines binding to the $\mathrm{Na}^{+} /$ $\mathrm{H}^{+}$exchanger regulatory factor family of PDZ proteins. Proc Natl Acad Sci USA 95(15):8496-8501. http://www.ncbi.nlm.nih.gov/ pubmed/9671706

28. Short DB, Trotter KW, Reczek D, Kreda SM, Bretscher A, Boucher RC, Stutts MJ, Milgram SL (1998) An apical PDZ protein anchors the cystic fibrosis transmembrane conductance regulator to the cytoskeleton. J Biol Chem 273(31):19797-19801. http://www.ncbi.nlm.nih.gov/pubmed/9677412

29. Cheng J, Moyer BD, Milewski M, Loffing J, Ikeda M, Mickle JE, Cutting GR, Li M, Stanton BA, Guggino WB (2002) A Golgiassociated PDZ domain protein modulates cystic fibrosis transmembrane regulator plasma membrane expression. J Biol Chem 277(5):3520-3529. https://doi.org/10.1074/jbc.M110177200

30. Arora K, Moon C, Zhang W, Yarlagadda S, Penmatsa H, Ren A, Sinha C, Naren AP (2014) Stabilizing rescued surface-localized
$\Delta$ f508 CFTR by potentiation of its interaction with $\mathrm{Na}(+) / \mathrm{H}(+)$ exchanger regulatory factor 1 . Biochemistry 53(25):4169-4179. https://doi.org/10.1021/bi401263h

31. Loureiro CA, Matos AM, Dias-Alves A, Pereira JF, Uliyakina I, Barros P, Amaral MD, Matos P (2015) A molecular switch in the scaffold NHERF1 enables misfolded CFTR to evade the peripheral quality control checkpoint. Sci Signal 8(377):ra48. https:// doi.org/10.1126/scisignal.aaa1580

32. Wang S, Yue H, Derin RB, Guggino WB, Li M (2000) Accessory protein facilitated CFTR-CFTR interaction, a molecular mechanism to potentiate the chloride channel activity. Cell 103(1):169 179. http://www.ncbi.nlm.nih.gov/pubmed/11051556

33. Raghuram V, Mak DO, Foskett JK (2001) Regulation of cystic fibrosis transmembrane conductance regulator single-channel gating by bivalent PDZ-domain-mediated interaction. Proc Natl Acad Sci USA 98(3):1300-1305. https://doi.org/10.1073/pnas.03153 8898

34. Benharouga M, Sharma M, So J, Haardt M, Drzymala L, Popov M, Schwapach B, Grinstein S, Du K, Lukacs GL (2003) The role of the $\mathrm{C}$ terminus and $\mathrm{Na}^{+} / \mathrm{H}^{+}$exchanger regulatory factor in the functional expression of cystic fibrosis transmembrane conductance regulator in nonpolarized cells and epithelia. J Biol Chem 278(24):22079-22089. https://doi.org/10.1074/jbc.M301030200

35. Cheng J, Wang H, Guggino WB (2004) Modulation of mature cystic fibrosis transmembrane regulator protein by the PDZ domain protein CAL. J Biol Chem 279(3):1892-1898. https:// doi.org/10.1074/jbc.M308640200

36. Sharma N, LaRusch J, Sosnay PR, Gottschalk LB, Lopez AP, Pellicore MJ, Evans T, Davis E, Atalar M, Na CH, Rosson GD, Belchis D, Milewski M, Pandey A, Cutting GR (2016) A sequence upstream of canonical PDZ-binding motif within CFTR COOHterminus enhances NHERF1 interaction. Am J Physiol Lung Cell Mol Physiol 311(6):L1170-L1182. https://doi.org/10.1152/ajplu ng.00363.2016

37. Benharouga M, Haardt M, Kartner N, Lukacs GL (2001) COOHterminal truncations promote proteasome-dependent degradation of mature cystic fibrosis transmembrane conductance regulator from post-Golgi compartments. J Cell Biol 153(5):957-970. http://www.ncbi.nlm.nih.gov/pubmed/11381082

38. McClure ML, Barnes S, Brodsky JL, Sorscher EJ (2016) Trafficking and function of the cystic fibrosis transmembrane conductance regulator: a complex network of posttranslational modifications. Am J Physiol Lung Cell Mol Physiol 311(4):L719-L733. https:// doi.org/10.1152/ajplung.00431.2015

39. Castellani C, Cuppens H, Macek M Jr, Cassiman JJ, Kerem E, Durie P, Tullis E, Assael BM, Bombieri C, Brown A, Casals T, Claustres M, Cutting GR, Dequeker E, Dodge J, Doull I, Farrell P, Ferec C, Girodon E, Johannesson M, Kerem B, Knowles M, Munck A, Pignatti PF, Radojkovic D, Rizzotti P, Schwarz M, Stuhrmann M, Tzetis M, Zielenski J, Elborn JS (2008) Consensus on the use and interpretation of cystic fibrosis mutation analysis in clinical practice. J Cyst Fibros 7(3):179-196. https://doi. org/10.1016/j.jcf.2008.03.009

40. Girardet A, Guittard C, Altieri JP, Templin C, Stremler N, Beroud C, Des Georges M, Claustres M (2007) Negative genetic neonatal screening for cystic fibrosis caused by compound heterozygosity for two large CFTR rearrangements. Clin Genet 72(4):374-377. https://doi.org/10.1111/j.1399-0004.2007.00850.x 